\title{
A hybrid approach based on SERVQUAL and fuzzy TOPSIS for evaluating banking service quality
}

\author{
Mahdi Karimi ${ }^{a}$, Milad Azizia* ${ }^{\text {, Hassan Javanshir }}{ }^{\mathrm{b}}$ and Seyed Mohammad Taghi Fatemi Ghomi ${ }^{\mathrm{c}}$
}

\author{
${ }^{a}$ Young Researchers and Elite Club, Kermanshah Branch, Islamic Azad University, Kermanshah, Iran \\ ${ }^{b}$ Department of Industrial Engineering, South Tehran Branch, Islamic Azad University, Tehran, Iran \\ ${ }^{c}$ Department of Industrial Engineering, Amirkabir University of Technology, 424 Hafez Avenue, 1591634311Tehran, Iran

\begin{tabular}{l}
\hline C H R O N I C L E \\
\hline Article history: \\
Received December 10, 2014 \\
Received in revised format: \\
March 2, 2015 \\
Accepted April 15, 2015 \\
Available online \\
April 16 2015 \\
\hline Keywords: \\
Ranking bank \\
SERVQUAL \\
TOPSIS \\
AHP
\end{tabular}

\section{A B S T R A C T}

\begin{abstract}
Quality of services in banking industry plays essential role in measuring the performance of banks. As customer awareness increases on the services offered by banks, expectations from service quality increases too. Presently, managers of banks use different financial factors such as deposits, credits, etc. to rank their banks. This paper uses SERVQUAL technique to measure customer satisfaction for 14 branches of a bank in city of Kermanshah, Iran. The study first statistically shows that customer satisfaction was not the same for all these banks and then using analytical hierarchy process and The Technique for Order of Preference by Similarity to Ideal Solution (TOPSIS) ranks these branches using five components of SERVQUAL method; namely tangibles, reliability, assurance, responsiveness and empathy.
\end{abstract}

(c) 2015 Growing Science Ltd. All rights reserved.

\section{Introduction}

Performance measurement plays essential role for making financial decisions and there are literally many studies for having reliable systems. Wu et al. (2012) performed an empirical investigation to weight the performance evaluation indices for higher education according to the official performance evaluation structure developed by the Taiwan Assessment and Evaluation Association (TWAEA) and ranked 12 private universities. They used a hybrid multiple-criteria decision-making (MCDM) model to reach these objectives. They utilized the analytic hierarchy process (AHP) to reach the first aim, but they used the VlseKriterijumska Optimizacija I Kompromisno Resenje (VIKOR) technique for the second objective by utilizing the AHP outcome. They also compared the official rankings of the 12 private universities with their ranking of the same universities. The study tried to help universities optimize their performances with efficiency. Amiri (2010) proposed a technique to provide a simple approach to evaluate alternative projects and helped the decision-maker select the best one for National

\footnotetext{
* Corresponding author.

E-mail address: miladazizi66@yahoo.com (M. Azizi) 
Iranian Oil Company by using six criteria of comparing investment alternatives as criteria in an AHP and fuzzy TOPSIS (The Technique for Order of Preference by Similarity to Ideal Solution) techniques. The AHP was implemented to analyze the structure of the project selection problem and to determine weights of the criteria, and fuzzy TOPSIS method was applied to calculate the final ranking. Awasthi et al. (2011b) presented a hybrid approach based on SERVQUAL and fuzzy TOPSIS for assessing service quality of urban transportation systems. They first developed a SERVQUAL based questionnaire to collect data for measuring transportation service quality. Next, they used the linguistic ratings through fuzzy TOPSIS to generate an overall performance score for each alternative. Kumar et al. (2009) determined the critical factors to access the level of service quality of banks by re-examining the SERVQUAL model, originally pioneered by Parasuraman et al. (1988). Bahia and Nantel (2000) presented a study performed in Canada to develop a reliable and valid scale for the measurement of the perceived service quality of bank services. The proposed scale is called banking service quality (BSQ) and consisted 31 items, which span six dimensions including effectiveness and assurance; access; price; tangibles; services portfolio and reliability.

\section{The proposed study}

This paper uses SERVQUAL technique to measure customer satisfaction for 14 branches of a bank in city of Kermanshah, Iran. Fig. 1 demonstrates the structure of the proposed study.

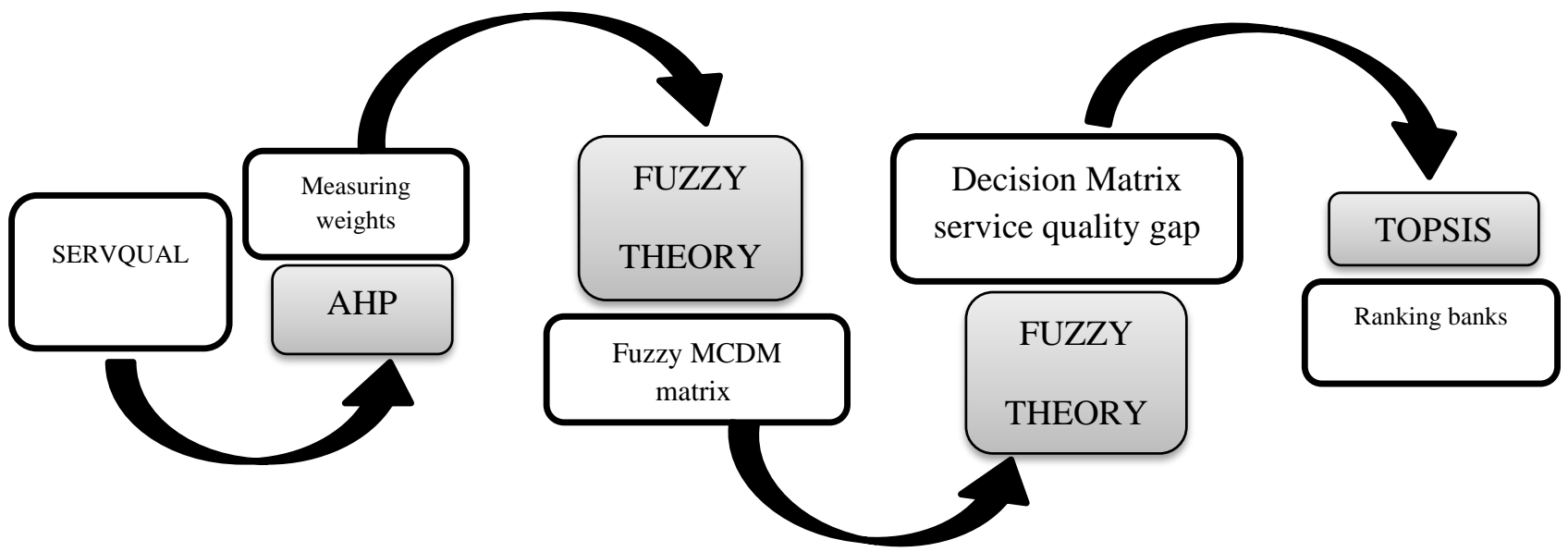

Fig. 1. Ranking banks

The proposed study uses SERVQUAL (Parasuraman et al., 1998; Angur et al., 1999) technique to measure customer satisfaction for 14 branches of a bank in city of Kermanshah, Iran. The study first statistically shows that customer satisfaction was not the same for all these banks and then using analytical hierarchy process and The Technique for Order of Preference by Similarity to Ideal Solution (TOPSIS) ranks these branches using five components of SERVQUAL method; namely tangibles, reliability, assurance, responsiveness and empathy. In addition, we use fuzzy numbers to handle uncertainty associated with numbers. Fig. 2 demonstrates the structure of SERVQUAL method.

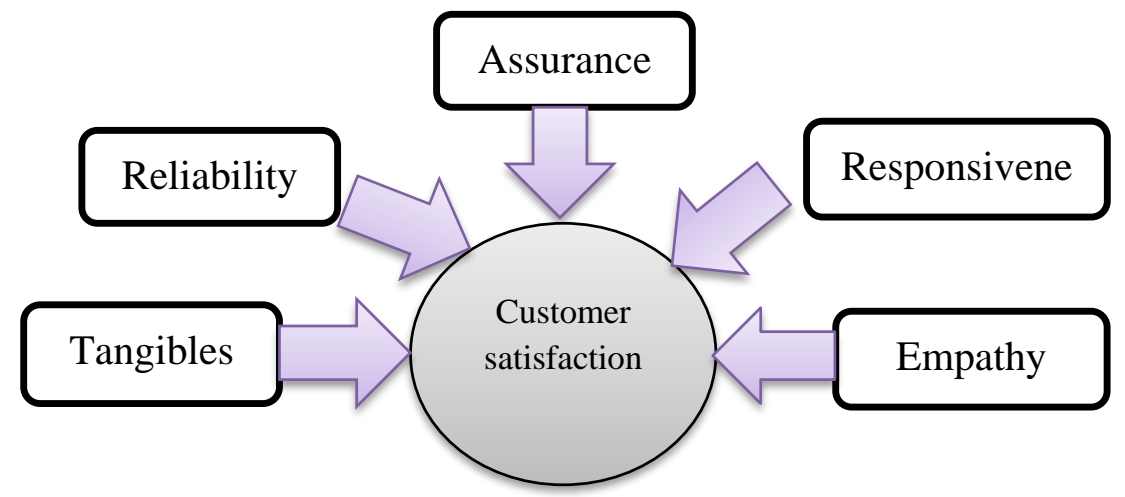

Fig. 2. The framework of customer satisfaction 
The proposed method of this paper measures all five components associated with customer satisfaction using SERVQUAL method. There are three main hypotheses associated with this study as follows,

1. There is a difference between perceived qualities of different branches of bank from customers' perspective.

2. There are significant differences in bank branches in terms of the priority of the constituent elements of perceived service quality.

3. There is a difference between customers' expectations and perceived qualities in different branches.

The last main hypothesis is investigated in terms of five components of SERVQUAL method; namely tangibles, reliability, assurance, responsiveness and empathy under five sub-hypotheses. There are also two questionnaires in this study. The first questionnaire is a standard SERVQUAL consists of 22 questions, which is arranged in five categories. The second questionnaire is related to assigning weights by pairwise comparison of different components in Likert scale. Cronbach alphas for two questionnaires are 0.80 and 0.77 , respectively. Fig. 3 demonstrates personal characteristics of the participants.

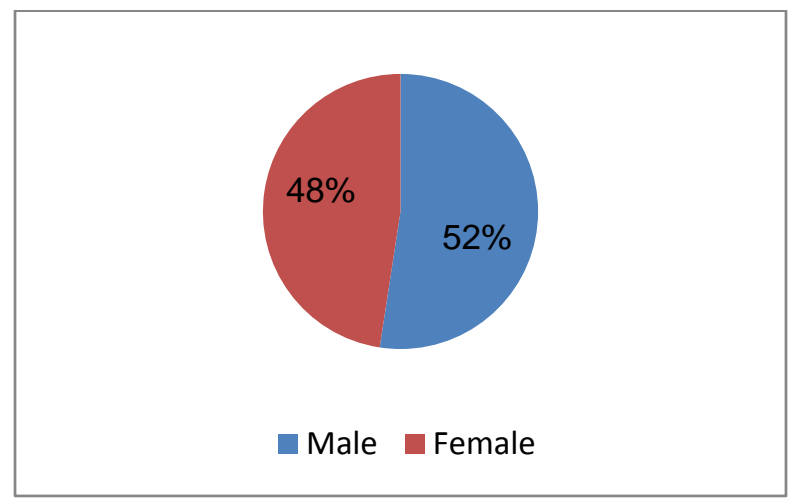

Gender

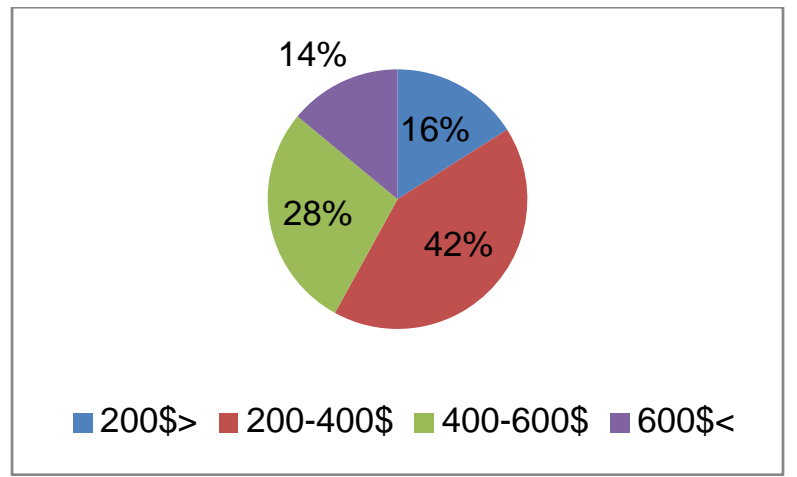

Income

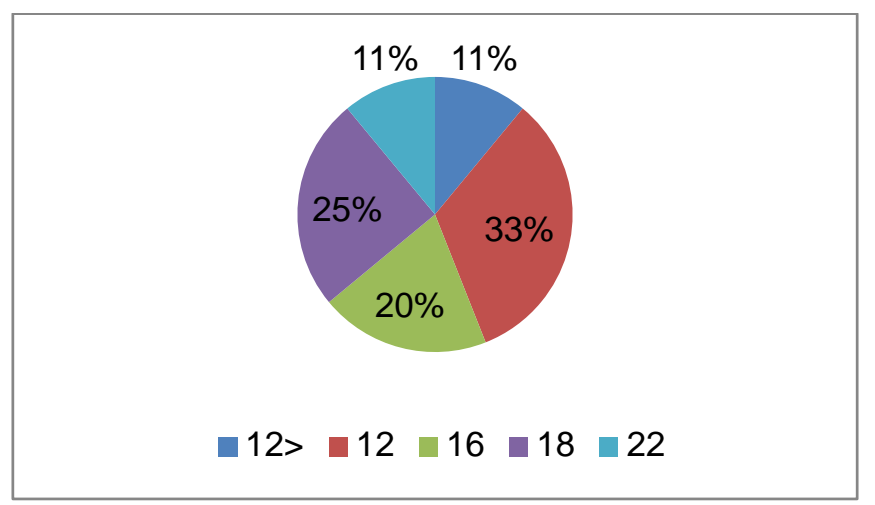

Years of education

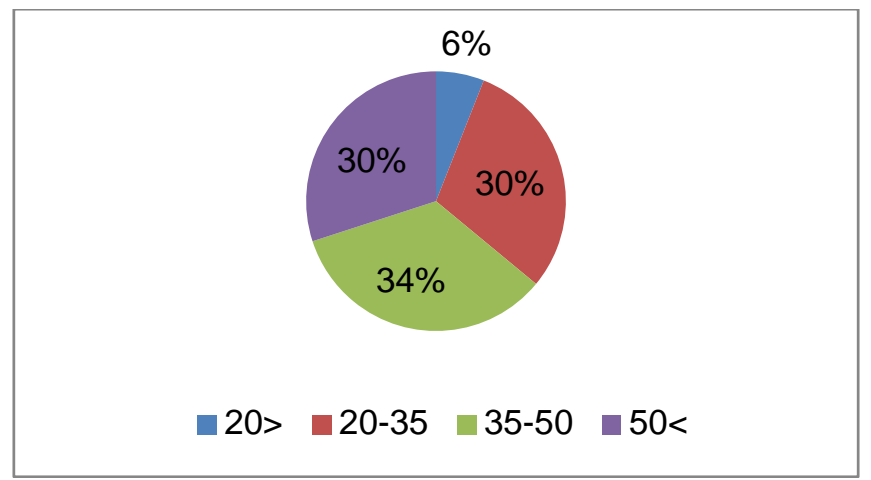

Age

Fig. 3. Personal characteristics of the participants

As we can observe from Fig. 3, about half of the participants in our survey were male, $56 \%$ of them had some university educations, 64\% were middle aged people and $70 \%$ of them earned between 200 to $600 \$$ of salary. Table 1 demonstrates the results of measuring means of customer expectations in terms of five SERVQUAL survey. In addition, Table 2 shows the results of measuring means of customer perception for five SERVQUAL survey. 


\section{Table 1}

Average of the five components of expected quality of services

\begin{tabular}{ccccccc}
\hline Branch & Tangible & Reliability & Assurance & Responsiveness & Empathy & $\begin{array}{c}\text { Expectation from } \\
\text { perception quality }\end{array}$ \\
\hline 1 & 6.8417 & 6.7833 & 6.7 & 6.6267 & 6.6467 & 33.5983 \\
2 & 6.9048 & 6.6786 & 6.8175 & 6.581 & 6.2762 & 33.2579 \\
3 & 6.925 & 6.975 & 6.2667 & 6.6067 & 6.6267 & 33.4 \\
4 & 6.6583 & 6.525 & 6.45 & 6.54 & 6.5533 & 32.7267 \\
5 & 6.8081 & 6.7965 & 6.8081 & 6.7767 & 6.8326 & 34.0221 \\
6 & 6.3417 & 6.7333 & 6.9333 & 6.6467 & 6.4238 & 33.0788 \\
7 & 6.7965 & 6.9593 & 6.4186 & 6.7767 & 6.6013 & 33.5525 \\
8 & 6.925 & 6.6 & 6.4833 & 6.7933 & 6.7067 & 33.5083 \\
9 & 6.575 & 6.55 & 6.6583 & 6.9333 & 6.4267 & 33.1433 \\
10 & 7 & 6.6778 & 6.475 & 6.68 & 6.54 & 33.3728 \\
11 & 6.8438 & 6.5469 & 6.3047 & 6.65 & 6.5 & 32.8453 \\
12 & 6.95 & 6.8938 & 6.1875 & 6.745 & 6.4 & 33.1763 \\
\hline 13 & 6.7458 & 6.9 & 6.7 & 6.9267 & 6.7933 & 34.0658 \\
\hline Mean & 6.7979 & 6.7437 & 6.5732 & 6.7217 & 6.5558 & 34.0343 \\
\hline
\end{tabular}

Table 2

Average of the five components of perception quality of services

\begin{tabular}{ccccccc}
\hline Branch & Tangible & Reliability & Assurance & Responsiveness & Empathy & Perception quality \\
\hline 1 & 5.8667 & 5.8733 & 6.1083 & 6.2833 & 6.4083 & 30.54 \\
2 & 6.2429 & 6.3619 & 4.9107 & 6.5179 & 5.3214 & 29.3548 \\
3 & 5.57 & 6.18 & 6.05 & 5.0417 & 6.7 & 29.4517 \\
4 & 5.48 & 6.16 & 5.8833 & 6.1417 & 5.4167 & 29.0817 \\
5 & 5.7256 & 5.1767 & 5.7384 & 5.9826 & 5.907 & 28.5302 \\
6 & 5.2933 & 5.8667 & 5.3583 & 6.0833 & 5.8917 & 28.4933 \\
7 & 5.2698 & 5.4744 & 5.3953 & 5.8953 & 5.7733 & 27.8081 \\
8 & 4.96 & 5.2933 & 6.1833 & 6.225 & 6.7667 & 29.4283 \\
9 & 6.06 & 5.0533 & 5.9167 & 6.0833 & 6.325 & 29.4383 \\
10 & 6.445 & 6.34 & 6.4167 & 6.2333 & 6.525 & 31.96 \\
11 & 6.1188 & 5.9688 & 5.7031 & 6.1016 & 6.2813 & 30.1734 \\
12 & 5.96 & 4.5 & 5.7563 & 5.775 & 4.2188 & 26.21 \\
13 & 5.42 & 5.4095 & 5.175 & 5.2527 & 5.2444 & 26.5017 \\
\hline 14 & 5.1029 & 6.0686 & 5.0214 & 6.4714 & 6.6071 & 29.2714 \\
\hline Mean & 5.9184 & 6.0305 & 5.6568 & 5.6438 & 5.6783 & 28.9279 \\
\hline
\end{tabular}

\subsection{The first hypothesis}

To examine the hypotheses of the survey, we need to compare the means of the firms as follows,

$\left\{\begin{array}{l}H_{0}: \mu_{1}=\mu_{2}=\cdots=\mu_{14} \\ H_{1}: \mu_{1} \neq \mu_{2} \neq \cdots \neq \mu_{14}\end{array}\right.$

where $\mu_{i} i=1, \ldots, 14$ represents the mean of customers' perception quality. To examine this hypothesis, the study uses one-way ANOVA test and Table 3 shows details of descriptive statistics of the study. Table 4 presents the summary of ANOVA test. According to the results of Table 4, the means of 14 groups are different. Therefore, the first hypothesis of the survey has been confirmed. 
Table 3

The summary of some basic statistics

\begin{tabular}{ccccc}
\hline Branch & Number & Mean & Standard deviation & Standard error \\
\hline 1 & 30 & 30.54 & 3.2791 & 0.59868 \\
2 & 42 & 29.3548 & 1.72743 & 0.26655 \\
3 & 30 & 29.4517 & 1.15695 & 0.21123 \\
4 & 30 & 29.0817 & 1.35006 & 0.24649 \\
5 & 43 & 28.5302 & 1.8071 & 0.27558 \\
6 & 30 & 28.4933 & 1.27582 & 0.23293 \\
7 & 43 & 27.8081 & 1.57959 & 0.24089 \\
8 & 30 & 29.4283 & 1.19926 & 0.21895 \\
9 & 30 & 29.4383 & 1.01851 & 0.18595 \\
10 & 30 & 31.96 & 0.77853 & 0.14214 \\
\hline 11 & 30 & 30.1734 & 1.23628 & 0.21855 \\
12 & 26.21 & 1.43657 & 0.22714 \\
\hline 13 & 40 & 26.5017 & 1.69092 & 0.30872 \\
\hline 14 & 30 & 29.2714 & 1.20784 & 0.20416 \\
\hline Sum & 35 & 28.9279 & 2.12613 & 0.09755 \\
\hline
\end{tabular}

\section{Table 4}

The summary of ANOVA test

\begin{tabular}{lccccc}
\hline Source of changes & df & Sum of Squares & Mean of Squares & F & P-Value \\
\hline Between groups & 13 & 977.929 & 75.225 & 29.774 & 0.0000 \\
Inside groups & 461 & 1164.748 & 2.527 & & \\
\hline Sum & 474 & 2142.678 & & & \\
\hline
\end{tabular}

\subsection{The second hypothesis}

To examine the second hypothesis of the survey, we consider the following hypothesis,

$\left\{\begin{array}{l}H_{0}: \mu_{1}=\mu_{2}=\cdots=\mu_{5} \\ H_{1}: \mu_{1} \neq \mu_{2} \neq \cdots \neq \mu_{5}\end{array}\right.$

where $\mu_{\mathrm{i}} \mathrm{i}=1, \ldots, 5$ represent the mean of customers' perception quality. To examine this hypothesis, the study uses one-way ANOVA test and Table 5 shows details of descriptive statistics of the study.

Table 5

The summary of some basic statistics

\begin{tabular}{lccc}
\hline Description & Number & Mean & Standard deviation \\
\hline Expected perception quality & 475 & 33.3922 & 0.93832 \\
Perception quality & 475 & 28.9279 & 2.12613 \\
Expected tangible & 475 & 6.7979 & 0.30631 \\
Expected reliability & 475 & 6.7437 & 0.31566 \\
Expected responsiveness & 475 & 6.7217 & 0.27881 \\
Expected trust & 475 & 6.5732 & 0.41471 \\
Expected empathy & 475 & 6.5558 & 0.38514 \\
Perception reliability & 475 & 6.0305 & 0.66113 \\
Perception tangible & 475 & 5.9184 & 0.92095 \\
Perception empathy & 475 & 5.6783 & 0.71021 \\
Perception trust & 475 & 5.6568 & 0.80356 \\
Perception responsiveness & 475 & 5.6438 & 0.81231 \\
\hline
\end{tabular}


Table 6 presents the summary of ANOVA test. According to the results of Table 6, the means of 5 groups are different. Therefore, the second hypothesis of the survey has been confirmed.

Table 6

The summary of ANOVA test

\begin{tabular}{lcccc}
\hline Source of changes & df & Sum of Squares & F & P-Value \\
\hline Perception tangible & 13 & 229.516 & 47.18 & 0.000 \\
Perception quality & 13 & 63.578 & 15.7 & 0.000 \\
Perception trust & 13 & 91.952 & 15.229 & 0.000 \\
Perception responsiveness & 13 & 156.158 & 35.359 & 0.000 \\
Perception empathy & 13 & 87.855 & 20.601 & 0.000 \\
\hline
\end{tabular}

\subsection{The third hypothesis}

In order to examine the third hypothesis of the survey, we compare the mean of customers' expectations with their perception in terms of five SERVQUAL components. The null hypothesis states the expectation is less than perception. Table 7 demonstrates the results of t-student test for five components. According to the results of Table 7, there is a significant difference between expectation and perception in terms of all SERVQUAL components.

\section{Table 7}

The summary of testing expectation and perception

\begin{tabular}{lccccccc}
\hline Component & Expectation & Perception & Difference & t-value & $\alpha$ & P-value & Result \\
\hline Quality & 33.3922 & 28.9279 & 4.3137 & -45.922 & 0.05 & 0.000 & Confirmed \\
Tangible & 6.7979 & 5.9184 & 0.8795 & -20.923 & 0.05 & 0.000 & Confirmed \\
Reliability & 6.7437 & 6.0305 & 0.7132 & -21.709 & 0.05 & 0.000 & Confirmed \\
\hline Assurance & 6.5732 & 5.6568 & 0.9164 & -23.494 & 0.05 & 0.000 & Confirmed \\
Responsiveness & 6.7217 & 5.6438 & 1.0779 & -27.269 & 0.05 & 0.000 & Confirmed \\
\hline
\end{tabular}

\section{Ranking methodology}

In this section, we present the implementation of fuzzy TOPSIS for ranking 14 branches of banks. The study first uses analytical hierarchy process (AHP) to rank the criteria and then it uses fuzzy TOPSIS (Yu et al., 2011) to rank them accordingly. The following summarizes the steps of the proposed method.

\subsection{Analytical hierarchy process}

Step 1 - Arrange the pairwise comparison matrix A by considering the ratio scale in Table 8.

\section{Table 8}

The ratio scale and definition of AHP

\begin{tabular}{cl}
\hline Intensity of importance & Definition \\
\hline 1 & Equally important \\
3 & Moderately important \\
5 & Strongly more important \\
7 & Very strong important \\
9 & Extremely more important \\
$2,4,6,8$ & Intermediate more important \\
\hline
\end{tabular}

Saaty (1980)

Step 2 - Let $C_{1}, C_{2}, \ldots . ., C_{n}$ be the set of elements, where $a_{i j}$ specify a quantified judgment on pair of elements $C_{i .}, C_{j .}$ the matrix A as below; 


$$
A=\left[a_{i j}\right]=\left[\begin{array}{cccc}
1 & a_{12} & \ldots & a_{1 n} \\
\frac{1}{a_{12}} & 1 & \ldots & a_{2 n} \\
\vdots & \vdots & \vdots & \vdots \\
\frac{1}{a_{1 n}} & \frac{1}{a_{2 n}} & \ldots & 1
\end{array}\right]
$$

where, $a_{i j}=1$ and $a_{j i}=\frac{1}{a_{i j}}, i . j=1,2, \ldots, n$

According to matrix $A$, the problem is to determine a set of numerical weights $W_{1}, W_{2}, \ldots ., W_{n}$ in front of $n$ element $C_{1}, C_{2}, \ldots ., C_{n}$. If $A$ is a consistency matrix, then the relationship between weights and judgments are specified by $a_{i j}=\frac{W_{j}}{W_{i}}$, for $(i, j=1,2,3, \ldots, n)$. The largest Eigenvalue $\lambda_{\max }$ is suggested by Saaty (1980) as follows;

$$
\lambda_{\max }=\sum_{j=1}^{n} a_{i j} \frac{W_{j}}{W_{i}}
$$

Let $A$ be the consistency matrix, then eigenvector $X$ can be measured as follows,

$$
\left(A-\lambda_{\max } I\right) X=0
$$

Therefore, the consistency index (C.I.) and random index (R.I.) verify the consistency ratio (C.R.). The consistency index and consistency rate are as follows,

$$
\text { C.I. }=\frac{\lambda_{\max }-n}{n-1} \text {, and C.R. }=\frac{C . I}{R . I}
$$

The number 0.1 is the accepted upper limit of C.R. If the final consistency ration is bigger than this value, the evaluation process could be accomplished one more time to improve consistency.

\subsection{Preliminary of fuzzy approach}

Fuzzy set theory is a class of objects with grades of membership used to model uncertainty and handle uncertainty by a membership function, which is between zero and one (Zadeh, 1965; Kutlu \& Ekmekçioğlu, 2012). It utilizes linguistic terms for decision makers’ preferences. This study uses fuzzy linguistics variables since experts judgments usually cannot be detected clearly.

Definition 1 - A fuzzy set $\tilde{A}$ in a universe of discourse $X$ is explained by membership function $\mu_{-}(x)$. It connects with each element $x$ in $X$, a real number in the interval[0,1]. The function value $\mu_{a}(x)$ is designated the grade of membership of $x$ in $\tilde{A}$. This study focuses on triangular fuzzy numbers. A triangular fuzzy number $\tilde{\mathrm{A}}$ is given by $\left(a_{1}, a_{2}, a_{3}\right)$, where $a_{3}>a_{2}>a_{1}$. The following equation expreses mathematical form of triangular fuzzy number and Fig. 4 also represents a triangular number. 
$\mu_{-}(x)=\left\{\begin{array}{cc}0, & x \leq a_{1} \\ \frac{x-a_{1}}{a_{2}-a_{1}}, & a_{1}<x \leq a_{2} \\ \frac{a_{3}-x}{a_{3}-a_{2}}, & a_{2}<x \leq a_{3} \\ 0, & x>a_{3}\end{array}\right.$

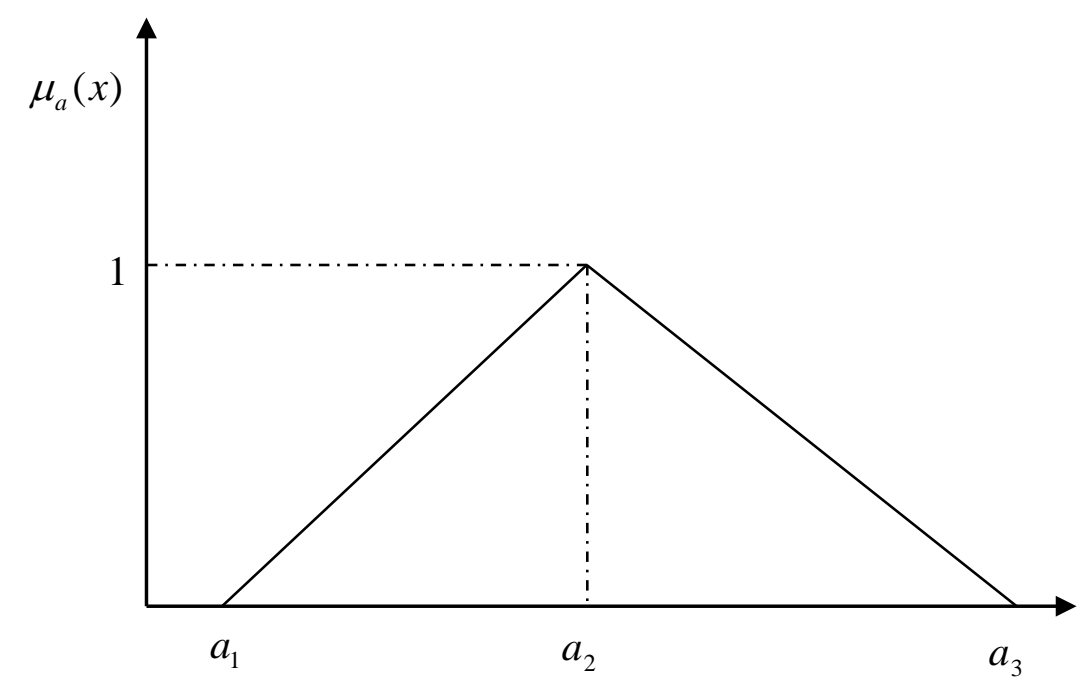

Fig. 4. Triangular number

Definition 2 - Let $a=\left(a_{1}, a_{2}, a_{3}\right)$ and $b=\left(b_{1}, b_{2}, b_{3}\right)$ be two triangular fuzzy numbers, the distance between them is computed as Eq. (5) as follows,

$$
\tilde{d(a, \tilde{b})}=\sqrt{\frac{1}{3}\left[\left(a_{1}-b_{1}\right)^{2}+\left(a_{2}-b_{2}\right)^{2}+\left(a_{3}-b_{3}\right)^{2}\right]}
$$

In addition, the Table 9 shows the operational equations of the two triangular fuzzy numbers.

\section{Table 9}

Basic equations of the two triangular fuzzy numbers

\begin{tabular}{ll}
\hline Operational law & Equations \\
\hline Addition & $(a+b)=\left(a_{1}+b_{1}, a_{2}+b_{2}, a_{3}+b_{3}\right)$ \\
Subtraction & $(a-b)=\left(a_{1}-b_{1}, a_{2}-b_{2}, a_{3}-b_{3}\right)$ \\
Multiplication & $(a \times b)=\left(a_{1} \times b_{1}, a_{2} \times b_{2}, a_{3} \times b_{3}\right), k(a)=\left(k a_{1}, k a_{2}, k a_{3}\right)$ \\
Division & $(a \div b)=\left(a_{1} \div b_{1}, a_{2} \div b_{2}, a_{3} \div b_{3}\right)$ \\
Inverse & $\left(a_{1}, a_{2}, a_{3}\right)^{-1}=\left(\frac{1}{a_{3}}, \frac{1}{a_{2}}, \frac{1}{a_{1}}\right)$ \\
\hline
\end{tabular}

\subsection{The fuzzy TOPSIS method}

TOPSIS method, as one of the most applied and practical techniques in classical multiple criteria decision making methods, was first introduced by Hwang and Yoon (1981) to analyze alternative solutions among each criterion and ultimately to determine the most efficient alternatives. The TOPSIS algorithm originates from having the shortest distance from the positive ideal solution (PIS) and farthest from negative ideal solution (NIS). Nevertheless, often for decision makers it would be challenge to assign a precise evaluation rating to an alternative. The advantage of using fuzzy approach in this study 
is to overcome the vagueness of human judgments and to receive relative importance of attributes (Yang \& Hung, 2007). The fuzzy TOPSIS distinguishes fuzzy evaluation of alternatives among criteria in traditional TOPSIS (Awasthi et al., 2010a; Wang et al., 2009). This study develops TOPSIS to a group decision process, which has been provided by Chen (2000). This proposed approach uses linguistic variables, which can be converted to fuzzy numbers easily. Now, the fuzzy TOPSIS procedure is introduced here (Awasthi et al., 2011a);

Step 1 -Suppose there are $j$ possible candidates called $A=\left\{A_{1}, A_{2}, \ldots . . A_{j}\right\}$, which are evaluated against $m$ criteria, $C=\left\{C_{1}, C_{2}, \ldots . . C_{m}\right\}$. The criteria weights are described by $w_{i}=\{i=1,2, \ldots . ., m\}$. The performance ratings of each decision maker $D_{k}(k=1,2, \ldots ., K)$ for each alternative $A_{j}(j=1,2, \ldots, n)$ respecting to criteria $C_{i}(i=1,2, \ldots ., m)$ are determined by $\tilde{R}_{k}=\tilde{X}_{i j k}(i=1,2, \ldots ., m ; j=1,2, \ldots ., n ; k=1,2, \ldots ., k)$ with membership function $\mu_{\tilde{R}_{k}}(x)$

Step 2 - Calculate aggregate fuzzy rating for the alternatives and the criteria. Suppose that the fuzzy rating of all decision maker about criteria are defined as triangular fuzzy numbers $\tilde{R}_{k}=\left(a_{k}, b_{k}, c_{k}\right)$, $k=1,2, \ldots . ., K$, then the aggregated fuzzy rating is given by $\tilde{R}=(a, b, c), k=1,2, \ldots . ., K$, where $a=\min _{k}\left\{a_{k}\right\}, \quad b=\frac{1}{k} \sum_{k=1}^{K} b_{k}, \quad c=\max _{k}\left\{c_{k}\right\}$.

If the fuzzy rating and importance weight of the $k^{\text {th }}$ decision maker are $\tilde{x}_{i j k}=\left(a_{i j k}, b_{i j k}, c_{i j k}\right)$ and $\tilde{w}_{i j k}=\left(w_{j k 1}, w_{j k 2}, w_{j k 3}\right), i=1,2, \ldots, m, j=1,2, \ldots \ldots, n$ respectively, then the integrated fuzzy ratings $\left(\tilde{x}_{i j}\right)$ of alternatives with respect to each criterion are given by $\tilde{x}_{i j}=\left(a_{i j}, b_{i j}, c_{i j}\right)$ where

$$
a_{i j}=\min _{k}\left\{a_{i j k}\right\}, \quad b_{i j}=\frac{1}{k} \sum_{k=1}^{K} b_{i j k}, \quad c_{i j}=\max _{k}\left\{c_{i j k}\right\} \text {. }
$$

The aggregated fuzzy weights $\left(\tilde{w}_{i j}\right)$ of each criterion are computed as $\tilde{w}_{j}=\left(w_{j 1}, w_{j 2}, w_{j 3}\right)$ where

$$
w_{j 1}=\min _{k}\left\{w_{1 j k}\right\}, \quad w_{j 2}=\frac{1}{k} \sum_{k=1}^{K} w_{j k 2}, \quad w_{j 3}=\max _{k}\left\{c_{j k 3}\right\} .
$$

Step 3 - Compute the fuzzy decision matrix

The fuzzy decision matrix for alternatives $(\tilde{D})$ and criteria $(\tilde{W})$ is constructed;

$$
\begin{aligned}
\tilde{D} & =\left[\begin{array}{cccc}
\tilde{x}_{11} & \tilde{x}_{12} & \ldots & \tilde{x}_{1 n} \\
\tilde{x}_{21} & \tilde{x}_{22} & \ldots & \tilde{x}_{2 n} \\
\ldots & \ldots & \ldots & \ldots \\
\tilde{x}_{m 1} & \tilde{x}_{m 1} & \ldots & \tilde{x}_{m n}
\end{array}\right], \quad i=1,2, \ldots ., m, \quad j=1,2, \ldots ., n \\
\tilde{W} & =\left(\tilde{w}_{1}, \ldots . ., \tilde{w}_{n}\right) .
\end{aligned}
$$

Step 4 - The raw data are normalized using a linear scale transforming to bring the various criterion scales on to a comparable scale. The normalized fuzzy decision matrix is given by

$$
\tilde{R}=\left[\tilde{r}_{i j}\right]_{m \times n}, \quad i=1,2, \ldots . ., m, \quad j=1,2, \ldots . ., n,
$$

Where

$$
\tilde{r}_{i j}=\left(\frac{a_{i j}}{c_{j}^{*}}, \frac{b_{i j}}{c_{j}^{*}}, \frac{c_{i j}}{c_{j}^{*}}\right) \text {, and } \quad c_{j}^{*}=\max _{i} c_{i j} \text { (benefit criteria) }
$$


$\tilde{r}_{i j}=\left(\frac{a_{j}^{-}}{c_{i j}}, \frac{a_{j}^{-}}{b_{i j}}, \frac{a_{j}^{-}}{a_{i j}}\right)$, and $\quad a_{j}^{-}=\min _{i} a_{i j}$ (cost criteria)

Step 5 -The weighted normalized matrix $\tilde{V}$ for criteria is calculated by multiplication of the weights $\left(\tilde{w}_{j}\right)$ of evaluation criteria with the normalized fuzzy decision matrix $\tilde{r}_{i j}$;

$\tilde{v}=\left[\tilde{v}_{i j}\right]_{m \times n}, \quad i=1,2, \ldots . . m, \quad j=1,2, \ldots . ., n$

Where

$\tilde{v}_{i j}=\tilde{r}_{i j}(\cdot) \tilde{w}_{j}$.

Step 6 - Calculation of the FPIS (fuzzy positive ideal solution) and FNIS (fuzzy negative ideal solution) for alternatives. FPIS and FNIS are computed as follows;

$$
A^{*}=\left(\tilde{v}_{1}^{*}, \cdots, \tilde{v}_{n}^{*}\right),
$$

where

$\tilde{v}_{j}^{*}=\max _{i}\left\{v_{i j 3}\right\}, i=1,2, \ldots ., m$ and $j=1,2, \ldots, n$

$A^{*}=\left(\tilde{v}_{1}^{-}, \cdots, \tilde{v}_{n}^{-}\right)$,

where

$\tilde{v}_{j}^{-}=\min _{i}\left\{v_{i j 1}\right\}, i=1,2, \ldots ., m$ and $j=1,2, \ldots, n$

Step7 - Compute the distance of each alternative from FPIS and FNIS. The distance $\left(d_{i}^{*}, d_{i}^{-}\right)$of each weighted alternative $i=1,2, \ldots ., m$ from the FPIS and FNIS is presented here;

$d_{i}^{*}=\sum_{j=1}^{n} d_{v}\left(\tilde{v}_{i j}, \tilde{v}_{j}^{-}\right), \quad i=1,2, \ldots, m$

$d_{i}^{-}=\sum_{j=1}^{n} d_{v}\left(\tilde{v}_{i j}, \tilde{v}_{i j}^{-}\right), \quad i=1,2, \ldots ., m$

where $d_{v}(\tilde{a}, \tilde{b})$ is the distance measurement between two fuzzy numbers $\tilde{a}$ and $\tilde{b}$

Step 8 - Compute the closeness coefficient $\left(c c_{i}\right)$ of each alternative. The closeness coefficient represents the distances to the fuzzy positive ideal solution and fuzzy negative ideal solution simultaneously. The closeness coefficient of each alternative is calculated by;

$c c_{i}=\frac{d_{i}^{-}}{d_{i}^{-}+d_{i}^{*}}, \quad i=1,2, \ldots ., m$

Step 9 - Rank the alternatives

\section{The results}

In this section, we present details of the implementation of AHP and fuzzy TOPSIS for ranking 14 branches of bank. We first present the results of the implementation of AHP. Table 10 shows the results 
of our implementation. Moreover, Table 11 and Table 12 present the fuzzy values given for the implementation of fuzzy TOPSIS.

\section{Table 10}

The results of the implementation of AHP

\begin{tabular}{lcccccc}
\hline & Tangible & Reliability & Trust & Responsiveness & Empathy & Mean \\
\hline Tangible & 0.1071 & 0.1067 & 0.2150 & 0.0499 & 0.0889 & 0.1135 \\
Reliability & 0.1870 & 0.1863 & 0.2047 & 0.1105 & 0.2700 & 0.1917 \\
Trust & 0.1704 & 0.3113 & 0.3422 & 0.5758 & 0.2700 & 0.3339 \\
Responsiveness & 0.4196 & 0.3293 & 0.1161 & 0.1954 & 0.2749 & 0.2671 \\
Empathy & 0.1159 & 0.0664 & 0.1220 & 0.0684 & 0.0963 & 0.0938 \\
\hline
\end{tabular}

\section{Table 11}

The summary of weights of expected

\begin{tabular}{cccccc}
\hline \multicolumn{2}{c}{ Tangible } & Reliability & Trust & Responsiveness & Empathy \\
\hline 1 & $(8.683,9.825,9.975)$ & $(8.567,9.767,9.983)$ & $(8.400,9.625,9.900)$ & $(8.253,9.573,9.947)$ & $(8.293,9.560,9.900)$ \\
2 & $(8.810,9.887,9.982)$ & $(8.357,9.560,9.833)$ & $(8.452,9.649,9.905)$ & $(8.162,9.457,9.848)$ & $(7.552,8.986,9.657)$ \\
3 & $(8.850,9.917,9.992)$ & $(8.950,9.975,10.000)$ & $(7.533,9.025,9.758)$ & $(8.213,9.553,9.947)$ & $(8.253,9.527,9.867)$ \\
4 & $(8.317,9.558,9.858)$ & $(8.050,9.408,9.867)$ & $(7.900,9.225,9.725)$ & $(8.080,9.420,9.853)$ & $(8.107,9.387,9.787)$ \\
5 & $(8.616,9.756,9.948)$ & $(8.593,9.756,9.959)$ & $(8.616,9.762,9.954)$ & $(8.554,9.735,9.958)$ & $(8.665,9.805,9.972)$ \\
6 & $(7.567,9.025,9.667)$ & $(8.467,9.667,9.933)$ & $(8.867,9.925,9.992)$ & $(8.293,9.580,9.920)$ & $(7.360,8.893,9.660)$ \\
7 & $(8.593,9.750,9.942)$ & $(8.919,9.959 .10 .000)$ & $(7.826,9.221,9.802)$ & $(8.554,9.726,9.949)$ & $(8.126,9.414,9.819)$ \\
8 & $(8.833,9.900,9.975)$ & $(8.200,9.575,9.975)$ & $(7.967,9.342,9.858)$ & $(8.587,9.787,9.993)$ & $(8.400,9.560,9.793)$ \\
9 & $(8.117,9.450,9.867)$ & $(8.100,9392,9.792)$ & $(8.317,9.575,9.908)$ & $(8.867,9.920,9.987)$ & $(7.840,9.193,9.693)$ \\
10 & $(9.00,10.00,10.00)$ & $(8.033,9.367,9.842)$ & $(7.950,9.283,9.775)$ & $(8.360,9.620,9.940)$ & $(8.080,9.393,9.833)$ \\
11 & $(8.688,9.797,9.945)$ & $(8.094,9.391,9.766)$ & $(7.594,9.102,9.781)$ & $(8.288,9.575,9.913)$ & $(7.488,8.819,9.406)$ \\
12 & $(8.900,9.950,10.00)$ & $(8.788,9.875,9.981)$ & $(7.325,8.838,9.600)$ & $(8.490,9.710,9.965)$ & $(7.770,9.140,9.670)$ \\
13 & $(8.483,9.675,9.917)$ & $(8.800,9.867,9.958)$ & $(8.400,9.667,9.967)$ & $(8.853,9.913,9.987)$ & $(8.587,9.753,9.953)$ \\
14 & $(8.529,9.693,9.929)$ & $(8.629,9.743,9.900)$ & $(9.829,9.900,9.986)$ & $(8.623,9.783,9.971)$ & $(8.474,9.669,9.920)$ \\
\hline
\end{tabular}

\section{Table 12}

The summary of weights of perception quality

\begin{tabular}{cccccc}
\hline & Tangible & Reliability & Trust & Responsiveness & Empathy \\
\hline 1 & $(7.874,9.319,9.866)$ & $(7.592,9.033,9.650)$ & $(7.217,8.783,9.583)$ & $(6.760,8.433,9.427)$ & $(6.753,8.340,9.260)$ \\
2 & $(5.804,7.369,8.441)$ & $(8.083,9.286,9.619)$ & $(5.018,6.673,7.958)$ & $(7.733,9.081,9.624)$ & $(7.495,8.871,9.462)$ \\
3 & $(8.408,9.592,9.850)$ & $(5.167,6.950,8.367)$ & $(7.108,8.617,9.400)$ & $(7.360,8.793,9.473)$ & $(5.967,7.680,8.887)$ \\
4 & $(5.892,7.542,8.683)$ & $(7.283,8.817,9.567)$ & $(6.833,8.317,9.133)$ & $(7.360,8.793,9.473)$ & $(6.013,7.700,8.873)$ \\
5 & $(6.901,8.355,9.116)$ & $(6.983,8.564,9.419)$ & $(6.488,8.157,9.209)$ & $(7.320,8.820,9.567)$ & $(6.516,8.065,9.014)$ \\
6 & $(6.783,8.442,9.433)$ & $(7.167,8.700,9.500)$ & $(5.742,7.517,8.825)$ & $(5.493,7.098,8.284)$ & $(5.627,7.447,8.807)$ \\
7 & $(6.547,8.180,9.198)$ & $(6.797,8.395,9.308)$ & $(5.820,7.547,8.756)$ & $(6.733,8.380,9.393)$ & $(5.581,7.363,8.684)$ \\
8 & $(8.050,9.342,9.767)$ & $(7.467,8.975,9.692)$ & $(7.883,9.200,9.667)$ & $(5.995,7.674,8.823)$ & $(7.840,9.240,9.773)$ \\
9 & $(7.650,9.092,9.708)$ & $(7.167,8.692,9.467)$ & $(6.833,8.492,9.475)$ & $(7.680,9.113,9.720)$ & $(7.127,8.673,9.473)$ \\
10 & $(8.050,9.342,9.767)$ & $(7.467,8.975,9.692)$ & $(7.883,9.200,9.117)$ & $(5.240,6.947,8.287)$ & $(7.840,9.240,9.773)$ \\
11 & $(7.563,9.000,9.633)$ & $(7.211,8.672,9.430)$ & $(6.406,8.070,9.117)$ & $(7.680,9.113,9.720)$ & $(7.238,8.744,9.519)$ \\
12 & $(3.644,5.369,6.969)$ & $(6.563,8.231,9.256)$ & $(6.513,8.244,9.319)$ & $(6.938,8.575,9.481)$ & $(6.920,8.480,9.320)$ \\
13 & $(5.958,7.617,8.767)$ & $(6.033,7.667,8.783)$ & $(5.400,7.217,8.633)$ & $(4.280,5.955,7.410)$ & $(5.887,7.667,8.940)$ \\
14 & $(8.214,9.514,9.907)$ & $(7.971,9.271,9.707)$ & $(5.150,6.914,8.314)$ & $(5.087,6.807,8.193)$ & $(5.274,7.063,8.457)$ \\
\hline
\end{tabular}

The numbers are combined as follows,

$$
d(\tilde{m}, \tilde{n})=\sqrt{\frac{\left[\left(m_{1}-n_{1}\right)^{2}+\left(m_{2}-n_{2}\right)^{2}+\left(m_{3}-n_{3}\right)^{2}\right]}{3}} .
$$

Therefore, we have 


\section{Table 13}

The results of gap between expected and perception

\begin{tabular}{cccccc}
\hline & Tangible & Reliability & Trust & Responsiveness & Empathy \\
\hline 1 & 0.5546 & 0.7302 & 0.8581 & 1.1255 & 1.1930 \\
2 & 2.4325 & 0.2555 & 2.8544 & 0.3537 & 0.1347 \\
3 & 0.3270 & 2.9514 & 0.3982 & 0.7141 & 1.7888 \\
4 & 1.9432 & 0.5853 & 0.8781 & 0.5830 & 1.6393 \\
5 & 1.3658 & 1.1981 & 1.5979 & 2.5249 & 1.6893 \\
6 & 0.5798 & 0.9682 & 2.3753 & 1.1763 & 1.3934 \\
7 & 1.5499 & 1.5735 & 1.6250 & 2.0015 & 1.9974 \\
8 & 0.2241 & 0.5955 & 0.4412 & 2.2980 & 2.6368 \\
9 & 0.3518 & 0.6992 & 1.0896 & 2.8800 & 0.5252 \\
10 & 0.6808 & 0.4070 & 0.0878 & 0.5058 & 0.1680 \\
11 & 0.8162 & 0.6853 & 0.9857 & 1.0014 & 0.1641 \\
12 & 4.3895 & 1.6511 & 0.6032 & 3.5755 & 0.6534 \\
13 & 1.9946 & 2.1506 & 2.3652 & 1.0030 & 2.0551 \\
14 & 0.2091 & 0.4801 & 2.9006 & & 2.5278 \\
\hline
\end{tabular}

Using the fuzzy TOPSIS method we may determine the distances as follows,

\section{Table 14}

The summary of distances

\begin{tabular}{cccc}
\hline$S_{1}^{-}$ & 0.1837 & $S_{1}^{*}$ & 0.0571 \\
$S_{2}^{-}$ & 0.1688 & $S_{2}^{*}$ & 0.1564 \\
$S_{3}^{-}$ & 0.1885 & $S_{3}^{*}$ & 0.1118 \\
$S_{4}^{-}$ & 0.1883 & $S_{4}^{*}$ & 0.0605 \\
$S_{5}^{-}$ & 0.1208 & $S_{5}^{*}$ & 0.1254 \\
$S_{6}^{-}$ & 0.1415 & $S_{6}^{*}$ & 0.1333 \\
$S_{7}^{-}$ & 0.1182 & $S_{7}^{*}$ & 0.1224 \\
$S_{8}^{-}$ & 0.1861 & $S_{8}^{*}$ & 0.0858 \\
$S_{9}^{-}$ & 0.1576 & $S_{9}^{*}$ & 0.1101 \\
$S_{10}^{-}$ & 0.2296 & $S_{10}^{*}$ & 0.0119 \\
$S_{11}^{-}$ & 0.1839 & $S_{11}^{*}$ & 0.0582 \\
$S_{12}^{-}$ & 0.1392 & $S_{12}^{*}$ & 0.1546 \\
$S_{13}^{-}$ & 0.0654 & $S_{13}^{*}$ & 0.1809 \\
$S_{14}^{-}$ & 0.1540 & $S_{14}^{*}$ & 0.1609 \\
\hline
\end{tabular}

Finally, the ranking of the 14 branches are given in Table 15 as follows,

\section{Table 15}

The results of ranking 14 branches

\begin{tabular}{ccc}
\hline Branch number & Efficiency & Rank \\
\hline 10 & 0.9507 & 1 \\
1 & 0.7629 & 2 \\
11 & 0.7596 & 3 \\
4 & 0.7568 & 4 \\
8 & 0.6844 & 5 \\
3 & 0.6277 & 6 \\
9 & 0.5887 & 7 \\
2 & 0.5191 & 8 \\
6 & 0.5149 & 9 \\
7 & 0.4913 & 10 \\
5 & 0.4907 & 11 \\
14 & 0.489 & 12 \\
12 & 0.4738 & 13 \\
13 & 0.2655 & 14 \\
\hline
\end{tabular}


As we can observe from the results of Table 15, the average efficiency of different branches is about 0.60 . While some banks maintained good customer satisfaction, the others did poorly and this method appears to be a good technique for performance measurement.

\section{Conclusion}

In this paper, we have presented an empirical investigation to measure the performance of some banks using a hybrid of SERVQUAL and fuzzy TOPSIS. The proposed study of this paper has been applied for measuring the performance of a governmental bank in city of Kermanshah, Iran. The results of our investigation have indicated that ranking banks based on customer satisfaction could be a better alternative methodology compared with traditional methods, which relied on financial figures. The results of this survey are consistent with findings of similar works reported by Awasthi et al. (2011b).

\section{Acknowledgement}

The authors would like to thank the anonymous referees for constructive comments on earlier version of this paper.

\section{References}

Amiri, M. P. (2010). Project selection for oil-fields development by using the AHP and fuzzy TOPSIS methods. Expert Systems with Applications, 37(9), 6218-6224.

Amy, H.I.L., Yan, K.H., Yu, L.C. (2011). Advances in mathematical and computatioal methods: addressing modern challenges of science, technology, and society. AIP Conference Proceedings, 1368, 185-188.

Angur, M. G., Nataraajan, R., \& Jahera Jr, J. S. (1999). Service quality in the banking industry: an assessment in a developing economy. International Journal of Bank Marketing, 17(3), 116-125.

Awasthi, A., Chauhan, S. S., \& Goyal, S. K. (2011a). A multi-criteria decision making approach for location planning for urban distribution centers under uncertainty. Mathematical and Computer Modelling, 53(1), 98-109.

Awasthi, A., Chauhan, S. S., Omrani, H., \& Panahi, A. (2011b). A hybrid approach based on SERVQUAL and fuzzy TOPSIS for evaluating transportation service quality. Computers \& Industrial Engineering, 61(3), 637-646.

Bahia, K., \& Nantel, J. (2000). A reliable and valid measurement scale for the perceived service quality of banks. international journal of bank marketing,18(2), 84-91.

Chen, C. T. (2000). Extensions of the TOPSIS for group decision-making under fuzzy environment. Fuzzy Sets and Systems, 114(1), 1-9.

Hwang, C. L. \& Yoon, K. (1981). Multiple Attribute Decision Making: Methods and Applications. New york: Springer- Verlag.

Kutlu, A. C., \& Ekmekçioğlu, M. (2012). Fuzzy failure modes and effects analysis by using fuzzy TOPSIS-based fuzzy AHP. Expert Systems with Applications, 39(1), 61-67.

Kumar, M., Tat Kee, F., \& Taap Manshor, A. (2009). Determining the relative importance of critical factors in delivering service quality of banks: an application of dominance analysis in SERVQUAL model. Managing Service Quality: An International Journal, 19(2), 211-228.

Meziani, A. S., \& Rezvani, F. (1990). Using the analytical hierarchy process to select a financing instrument for a foreign investment. Mathematical and Computer Modelling, 13(7), 77-82.

Parasuraman, A., Zeithaml, V. A., \& Berry, L. L. (1988). Servqual. Journal of retailing, 64(1), 12-40.

Saaty, T. (1980). The analytic hierarchy process. New york: Mc Grae-Hill .

Wang, J. W., Cheng, C. H., \& Huang, K. C. (2009). Fuzzy hierarchical TOPSIS for supplier selection. Applied Soft Computing, 9(1), 377-386.

Wu, H. Y., Chen, J. K., Chen, I., \& Zhuo, H. H. (2012). Ranking universities based on performance evaluation by a hybrid MCDM model. Measurement, 45(5), 856-880. 
Yang, T., \& Hung, C. C. (2007). Multiple-attribute decision making methods for plant layout design problem. Robotics and Computer-Integrated Manufacturing,23(1), 126-137.

Yu, X., Guo, S., Guo, J., \& Huang, X. (2011). Rank B2C e-commerce websites in e-alliance based on AHP and fuzzy TOPSIS. Expert Systems with Applications, 38(4), 3550-3557.

Zadeh, L. A. (1965). Fuzzy sets. Information and Control , 338-353 .

Zimmermann, H. J. (1992). Fuzzy Set Theory and Its Applications Second, Revised Edition. Kluwer academic publishers 